\title{
Reconciliar dos naturalezas en el mismo cuerpo
}

Reconciling two selves in the same body

\author{
Gresilda A. Tilley-Lubbs ${ }^{1}$ \\ Virginia Tech Univesity
}

Forma de citar: Tilley-Lubbs, G. (2015). Reconciling two selves in the same body. Revista CES Psicología, 9(1), 135-149.

\begin{abstract}
Resumen
Durante su participación en un congreso con otros pedagogos críticos, un amigo le comentó a la autora que exhibe personalidades completamente diferentes dependiendo del idioma que habla. Con este poema autoetnográfico, la autora presenta lo que descubrió después de pasar más de un año practicando la reflexión y la introspección sobre sus dos Selves. Se dio cuento de que sus epistemologías y ontologías eran diferentes según la naturaleza dominante, y también que tenía dos maneras distintas de navegar por la vida dependiendo del idioma que hablara. En resumen, la autora utiliza la metodología de autoetnografía para examinar cómo el poder y el privilegio inciden en sus acciones y sus palabras, dependiendo de si piensa en inglés o en español.
\end{abstract}

Palabras clave: Reflexión, Introspección, Autoetnografía Crítica, Pedagogía Crítica, Bilingüismo.

\begin{abstract}
While participating in a congress with other critical pedagogues, the author became aware of her two Selves: the US English-speaking Self and the Mexican Spanish-speaking Self. With startling clarity, she realized why people had been telling her that she exhibits totally different personalities based on the language she is speaking. More surprisingly, she realized that her epistemologies and ontologies were diametrically opposed depending on the dominant Self. Using the lens of autoethnography, she examines how power and privilege determine her actions and her words depending on whether she is thinking in English or in Spanish.
\end{abstract}

Keywords: Reflection, Introspection, Critical Autoethnography, Critical Pedagogy, Bilingualism.

DOI: http://dx.doi.org/10.21615/cesp.9.1.9

1 Ph.D. Associate Professor of ESL and Multicultural Education Faculty of Teaching and Learning School of Education Virginia Tech Blacksburg, Virginia, Estados Unidos. glubbs@vt.edu 


\section{Barcelona, España}

Octubre 2013

Hablando en español,

algo que hago frecuentemente

tanto en el trabajo y con las amistades.

Hablando español "con fluidez"-

hasta puntos variados

dependiendo de

el cansancio,

el si me siento en mi ambiente,

el contacto que haya tenido con hispanoparlantes.

Nada de lo que pueda depender-nunca.

Una copa de Malbec

puede quitarme algo de timidez y soltarme la lengua

hasta que me gane el cansancio. . .

para apagar el cerebro-

no es siempre algo bueno.

Mi amigo mexicano Luis y yo

siguiendo a mi esposo Dan, y a

nuestros amigos Shirley y Eelco

por una calle estrecha y serpenteante.

Hablando en español.

Agotamiento después del vuelo transatlántico.

Casi vencida.

Tan concentrada en nuestra conversación

para poder sentirme en mi ambiente

con un amigo muy querido,

nuestras reuniones esporádicas durante el año,

manteniendo contacto regular

por Skype para comentar proyectos de trabajo.

Pensando en nuestro congreso anual del instituto de pedagogía crítica, que se llevaría a cabo al siguiente año en Chihuahua.

Colaborando con el Instituto de la Pedagogía Crítica,

el IPEC,

para integrarnos con colegas, estudiantes, la comunidad.

Quedándonos atrás.

Hablando en español. 
Pasando por tiendas cerradas-

teléfonos, medicinas herbales, productos agrícolas.

Luces de un tono amarillo brillando en los cafés,

un resplandor tenue

calentando la tarde fresca de octubre.

Shirley nos pregunta en inglés:

"Luis, ¿dónde está ese café

donde comimos la otra noche?"

Un cambio de conversación

en tema e idioma.

Rápidamente recorriendo las cuadras,

platicando sobre cafés,

Barcelona,

la vida.

Todo en inglés.

En español.

Luis se vuelve hacia mí:

"Hermana, tú eres una persona completamente diferente

hablando español.

En inglés el lenguaje corporal y las expresiones faciales son diferentes.

Aún tu voz es diferente.

Eres dos personas distintas."

Parando y clavando los ojos en Luis.

¿Será que piense y me comporte de una manera diferente

en español?

¿Es sólo el idioma?

¿O es la comodidad y la intimidad

de hablar con amigos queridos como Luis,

quien me llama su hermana?

Hablando con personas desconocidas

muchas veces sin poder hablar.

En inglés o en español.

Hablando con amigos mexicanos íntimos con cierta libertad de ser yo misma.

¿Sería posible que Luis se diera cuenta de eso?

¿O es más complicado? 
Llegando a nuestro destino sentados en un café pequeño comiendo comida catalana bebiendo sangría y vino tinto siguiendo nuestra conversación en un grupo.

En inglés.

Olvidadas las observaciones de Luis.

Mis dos Selves conjuntos.

Por el momento.

En días anteriores con Luis y con otros amigos mexicanos:

Sandra, Rafa, Marina y Sofía.

Visitas diarias al CREA,

el instituto de investigaciones en la Universidad de Barcelona.

Trabajando con los estudiantes que se preparan para ser maestros.

Observando clases primarias y de adultos,

pasando los días pensando y viviendo en español

pero como extranjera,

no como si estuviera en México.

Como miembro del grupo mexicano.

Todos observadores y forasteros en un país extranjero

donde por casualidad compartimos el idioma.

Durante el día en español.

Por la noche en inglés.

Dan, Shirley y Eelco.

Luis, Sandra, Rafa, Marina, Sofía.

La cena.

Más conversación.

En inglés.

En español.

El interruptor de la computadora en mi cerebro

alternando entre

el español y

el inglés. 
Igual a lo que pasa con mi trabajo.

Es natural,

normal.

Nuestros amigos de Chihuahua hablaban poco inglés.

No como Luis-

mexicano nuevo mexicano,

viviendo en Estados Unidos en Nuevo México,

completamente bilingüe.

Las tardes bilingües.

Interpretación para los angloparlantes

cuyo español es limitado.

Interpretación para los hispanoparlantes

cuyo inglés es limitado.

Alternando.

Viviendo ni en un espacio ni en otro.

Bilingüe.

Bicultural.

Valletta, Malta

Octubre 2013

Luis regresa a su casa en Nuevo México.

Los demás nos marchamos para Malta

para la junta anual del Congreso de Pedagogía Crítica.

Por la tarde del segundo día

nos reunimos al lado de la alberca del hotel

en grupos pequeños que comparten intereses.

Mi grupo va a discutir las comunidades-

cómo trabajamos en comunidades,

cómo nuestro trabajo en la comunidad incide en nuestro trabajo académico.

Mary habla desde su silla al lado de la alberca.

“Bien, ¿cuál es el tema que debemos desarrollar?”

Trato de establecer un foco de atención.

"El trabajo en la comunidad.

¿Qué hacemos en la comunidad?"

Antonia se mete en la conversación:

"Necesitamos considerar las inequidades del capitalismo.

Los latinos en Estados Unidos se han metido en un enredo

por las injusticias del capitalismo." 
Contrargumento en un tono estridente:

“El otro grupo aborda los marcos teóricos.

Nosotros nos centramos en nuestro trabajo en la comunidad."

Tenemos que mantenernos enfocados.

Antonia insiste:

"Pero no puedes hablar de la comunidad latina en Estados Unidos sin hablar del capitalismo.

Mi cuerpo se pone rígido.

No nos podemos desviar del tema acordado.

La discusión sigue por bastante tiempo.

Antonia y yo nos respondemos la una a la otra.

Los tonos de voz muy irritados

como frecuentemente predomina en las discusiones académicas.

Alguien interrumpe el ciclo disruptivo.

"Voy a nadar en el Mediterráneo."

Poco a poco la gente se para y se aleja.

Escondo mi molestia

y voy en busca de Dan

para descargar el enojo.

Seguimos reuniéndonos y discutiendo.

Las comidas y las ocasiones sociales predominan en esos días.

El sábado, el último día de la junta.

Nos reunimos en el Hotel Castillo.

Un café al aire libre en la azotea.

Una vista bella de la ciudad blanca.

Tomando café

redondeando una semana

de emociones y pensamientos e ideas.

Hablando en inglés.

Adaptándonos a la mayoría de las personas.

Todas hablando el inglés a cierto nivel de fluidez-

un grupo internacional:

canadienses, australianos, ingleses,

estadounidenses, holandeses, mexicanos.

Sandra, Rafa, Marina y Sofía ahora pueden seguir la conversación en inglés un poco 
con mi interpretación intermitente.

Comentarios casuales se presentan, nuestros pensamientos ya en camino para el aeropuerto.

La mayoría de la gente se despide y sale.

Antonia nos acompaña ahora

y empieza a hablar en español.

“Ojalá que en México pasemos tiempo trabajando en comunidadesuna oportunidad de ver el impacto del capitalismo

en las comunidades mexicanas."

Antonia habla de los mismos asuntos

de los cuales hablaba ese día al lado de la alberca en el hotel.

Escucho en español.

Todo parece lógico.

Inclino la cabeza,

concentrada en sus palabras,

cuerpo tenso con concentración,

no con enojo.

Y me acuerdo de las palabras de Luis.

¿Seré una persona diferente en español?

Dos maneras de pensar y reaccionar.

Antes se me puso tenso el cuerpo.

Ahora me relajo con las palabras de Antonia.

Mi Self angloparlante se transformó a mi Self hispanoparlante.

Una conversación centrada en el marxismo y el capitalismo

en el contexto de comunidades marginadas y vulnerables

me parece lógico.

En español digo:

"Antonia, lo siento tanto.

Por favor, perdona mi rudeza del otro día.

Me doy cuenta de que mis reacciones

fueron el resultado de pensar como gringa.

Ahora que estoy pensando en español,

pienso de una manera diferente.

Todo lo que dices parece lógico.

No tenía ningún sentido para mí en inglés."

Antonia se pone de pie para abrazarme.

Pero después de salir de su presencia, pienso en inglés.

Todavía escéptica sobre el marxismo

como aspecto integral a mi trabajo en la comunidad. . . . 
¿Es un asunto de la amistad?

¿Del idioma?

Si tuviéramos la misma conversación

otra vez en inglés

¿cómo reaccionaría?

Champaign-Urbana, Illinois

Mayo 2014

Presento la forma narrativa de este poema

en el Congreso Internacional de Investigación Cualitativa.

Primero en español

para el Día en Español y Portugués.

Estoy leyendo las palabras

que originalmente construyeron una identidad

con mexicanos.

Leyendo y presentándome

dejo de hablar.

"No puedo seguir."

Me doy cuenta de que

me estoy apropiando de la identidad.

Tengo tanto poder y privilegio.

No puedo apelar a la misma identidad de ellos

quienes son tan oprimidos en mi país.

El siguiente día

en inglés

pero con una explicación de lo que pasó en español.

Más preguntas que respuestas.

Guanajuato, México

Junio 2014

Otro congreso.

En español.

Presentando un ensayo sobre la autoetnografía crítica (Tilley-Lubbs, 2014).

Presentándome.

La carrera en la literatura española.

Maestra de español a todos los niveles.

Investigadora en la comunidad hispanoparlante.

Acabo con mi presentación.

César, un amigo y colega mexicano de hace muchos años, dice:

"Hiciste tu carrera en la literatura española.

¿Por qué no citas a ningunos de esos autores en tu trabajo?" 
Aturdida.

"La autoetnografía crítica se concentra en

la autoetnografía

y la pedagogía crítica.

Es natural que me refiera a

Carolyn Ellis, Art Bochner, Laurel Richardson.

Paulo Freire, Joe Kincheloe, Shirley Steinberg."

¿Quiénes eran tus autores favoritos en la literatura española?"

Saco a la luz las memorias de hace muchos años

a la Universidad de Illinois.

Unamuno, Azorín.

La Generación del '98.

Fascinada por su disección de la apatía

experimentada por los españoles

después de la Guerra entre España y los Estados Unidos

y la pérdida de un imperio.

García Lorca, Muñoz.

Censurados por el gobierno de Franco.

Sus voces silenciadas.

El exilio.

Ana María Matute.

Encontrando la belleza de la vida después de

una Guerra Civil devastadora.

Neruda, Mistral.

La poesía inundando mi alma con más belleza

mientras las palabras forman imágenes de la añoranza

en mi mente.

En mi intelecto.

Jorge Luis Borges.

Involucrándome en la red mágica

de laberintos y

palabras que se caen la una sobre la otra y

crean imágenes que caen dentro de

las zonas más profundas de mi alma

mientras me sumerjo en los misterios místicos del judaísmo.

Los ojos de César se clavan en los míos.

“¿No puedes ver cómo esos son los autores

que determinaron tu modo de pensar?

¿No puedes ver cómo se integran en tu trabajo actual?

Todo lo que acabas de decir tiene sus raíces en esa literatura. 
Necesitas citar a esos autores.

Déjales saber a esos investigadores en los Estados Unidos

lo que tenemos que ofrecer."

Pasmada.

Sin palabras.

El caleidoscopio se mueve.

La nueva pintura contesta tantas preguntas mías.

Los colores combinan y se transforman.

Lo abstracto se hace más definido,

pero todavía inestables.

Recuerdo la pintura de Frida Kahlo,

Las dos Fridas

capturando su conflicto

con su identidad europea/indígena.

Mis dos Selves son diferentes.

Tratando con la etnicidad en cierto sentido,

pero de una manera distinta.

Soy apalacha.

Tengo raíces en los Montes Apalaches

con herencia principalmente inglesa, escocesa, irlandesa e indígena.

Mi bisabuelo Chéroqui.

La misma genealogía muestra

un pariente lejano en la Armada Española

que naufragó en las orillas de Irlanda en 1588.

Siendo imposible regresar a su hogar,

se queda en Irlanda,

anglicaniza su apellido.

Téllez se convierte en Tilley.

El resto de la historia es lo esperado.

Las historias de hace muchos años.

No soy ni española ni indígena.

Crecí en Estados Unidos,

mi hogar por toda la vida.

La piel blanca.

El inglés mi lengua materna.

Ambos la fuente de mi poder y privilegio.

Diferente de quienes crecían indígenas

o "hispanos" en los Estados Unidos.

Mi herencia de Virginia Occidental

como la hija de un minero de carbón.

Mi batalla constante con cuestiones de autoestima- 
los virginianos occidentales considerados rústicos, campesinos sin educación (Tilley-Lubbs, 2011).

Pero nunca experimenté la discriminación, la pérdida de derechos humanos experimentada por muchos indígenas e hispanos diariamente.

Soy gringa, gringa pura.

Ciudadana estadounidense pura.

A pesar del título de "mi hija cubana" otorgado por mi amiga cubana querida, Conchita, quien me llamó "su hija cubana,"

declarando que yo era más cubana que sus hijas, a quien le llamé mi mamá cubana.

Así que ¿cómo explico la suposición/presunción de otra identidad al hablar español?

¿Cómo explico por qué nunca tuve que aprender español?

Dos años de francés en la prepa-

no había más en mi prepa rural en Illinois.

Cambiando al españolpero ya lo conocía.

Completé tres años en dos, entonces seguí la carrera de español en la Universidad de Illinois.

La licenciatura.

La maestría en la literatura española.

El certificado de estudios en español de la Universidad de Salamanca.

Toda segunda naturaleza

fluyendo de la boca tan fácilmente como el inglés.

Nunca batallando con las formas de los verbos,

ni siquiera el subjuntivo.

Leyendo de una forma obsesiva en español, escribiendo ensayos con casi la misma facilidad como en inglés.

Los estudiosos escribiendo en su lenguaje aprendido tienen menos acceso al sentimiento emocional del lenguaje (Pavelenko, 2005).

No es mi caso. 
¿O lo es?

Creía que el inglés era mi lenguaje práctico,

El español mi lenguaje para

la filosofía,

la poesía,

los pensamientos profundos,

los discursos significativos.

Sin embargo...

Diciembre 2014/Enero 2015

Una discusión con Silvia, otra amiga y colega mexicana de mucho tiempo.

Palabras acaloradas.

El enojo en su correo electrónico.

Mi respuesta...

en inglés.

Mientras generalmente nos escribimos

en español.

Mientras escribo, reflexiono en un correo electrónico a Silvia:

¿Por qué escogí escribir en inglés?

¿Era porque

no podía decir lo que pensaba en español?

También tenía miedo de ser honesta

y de sonar dura e hiriente,

dolorosamente consciente

de que no estoy escribiendo en mi lengua materna.

¿Es qué el español es mi lenguaje para ser una

"persona buena y simpática"?

¿Es que me encanta el español como manera de ser

exótica y romántica?

¿Por qué me parece burdo hablar de ciertos temas en inglés?

¿Por qué me parece natural el español

para expresar el amor radical (Freire, 1970)

de la pedagogía crítica en mi trabajo?

¿Por qué me ayuda el español a mover la pedagogía crítica más allá de un marco teórico 
a un estilo de vida,

una manera de pensar en el mundo?

En inglés, estoy comprometida con la pedagogía crítica

como una teoría.

Chihuahua, México

Octubre 2014

Otro congreso sobre la pedagogía crítica.

Planteo estas preguntas

al leer un pasaje del ensayo original.

Más tarde Rodney se acerca a mí.

"¿Por qué te importa?

Eres un puente-

un puente entre

dos mundos: angloparlante

e hispanoparlante.

Acepta tu papel."

Dan hace la pregunta difícil:

"¿Y qué?

¿Qué quiere decir todo esto?”

Contesto que para decir verdad, no sé.

No escucho voces en la cabeza.

Sólo expreso mi reacción visceral,

fundamental,

dentro-de-mi-alma sentimientos de identidad

a resolver.

O no.

No es que

"Al fin me aceptan sin reserva."

No "Es padre hablar con fluidez en español."

No son otras afirmaciones similares de mí misma.

Me lo pregunté antes

¿Es qué me esté apropiando de la identidad

O es qué desempeñe mi realidad (Tilley-Lubbs, 2012)?

Trabajando en la comunidad,

desempeñando mi ser forastera/no forastera (Tilley-Lubbs, 2012),

interpretando,

socializando.

Ser la abuela de un nieto mexicano americano,

desempeñando mi ser no forastera/forastera (Tilley-Lubbs, 2012).

La madre/abuela sustituta de amigas mexicanas. 
Desempeñando mi ser forastera/enterada (Tilley-Lubbs, 2012).

La amistad basada en las conexiones intelectuales y de corazón. Siguiendo adelante pasado el turismo exótico del Otro.

Llegando a ver a los miembros de la comunidad como individuos, no todos amigos... algunos conocidos. Algún desencanto.

El título de este poema

sugiere que yo deseo

reconciliar mis dos Selves dentro del mismo cuerpo, pero ¿es verdad?

¿Es posible?

¿Es deseable?

¿Aún hay dos Selves?

¿O es qué sencillamente he hecho borrosas las fronteras geográficas, culturales, lingüísticas (Tilley-Lubbs, 2012)?

Creando un espacio poroso, indefinible,

indescriptible.

Moviendo en el intermedio. posicionamiento visible/invisible.

Escribo como investigación (Richardson, 2000), pero las respuestas todavía me eluden.

Voy a seguir buscando, escribiendo para conectar lo personal con lo sociocultural (Ellis, 2004), uniendo Mystory (Pelias, 2013; Ulmer, 1989) con los mundos que me determinaron. 


\section{Referencias}

Ellis, C. (2004). The ethnographic I: A methodological novel about autoethnography. Walnut Creek, CA: AltaMira.

Freire, P. (1970). Pedagogy of the oppressed. Bergman Ramos, M. (Trans). New York: Continuum Publishing

Pavelenko, A. (2005). Emotions and multilingualism. New York, NY: Cambridge University.

Pelias, R. (2013). Writing autoethnography: The personal, poetic, and performative as compositional strategies. In S.H. Jones, T.E. Adams, E C. Ellis (Eds.), Handbook of autoethnography (pp. 384-405). Walnut Creek, CA: Left Coast.

Richardson, L. (2000). Writing: A method of inquiry. In N. K. Denzin \& Y. S. Lincoln (Eds.). Handbook of Qualitative Research ( $2^{\text {nd }}$ ed.). (pp. 923-949). Thousand Oaks, CA: Sage.

Tilley-Lubbs, G. A. (2014). La autoetnografía crítica y el Self vulnerable como investigadora. REMIE: Multidisciplinary Journal of Educational Research, 4(3), 268-285.

Tilley-Lubbs, G. A. (2013). The baptism/El bautizo. Qualitative Research in Education, 2(1), 27-37. doi: 10:4471/qre.2013.14

Tilley-Lubbs, G. A. (2011e). The coal miner's daughter gets a Ph.D. Qualitative Inquiry, 17(9). doi: $10.1177 / 1077800411420669$

Ulmer, G. (1989). Teletheory: Grammatology in the age of video. New York: Routledge. 